\title{
Characteristics of Urban Sustainability in the Cases of Multi Commercial Complexes from the Perspective of the "Ground"
}

\author{
Soomi Kim ${ }^{1, *}$ and Jiae Han ${ }^{2, *}$ \\ 1 School of Architecture, Soongsil University, Seoul 156743, Korea \\ 2 Department of Architectural Engineering, Hongik University, Sejong 30016, Korea \\ * Correspondence: soomikim@ssu.ac.kr (S.K.); jhan@hongik.ac.kr (J.H.); \\ Tel.: +82-2-820-0991 (S.K.); +82-44-860-2021 (J.H.) \\ Academic Editor: Tan Yigitcanlar \\ Received: 6 February 2016; Accepted: 27 April 2016; Published: 4 May 2016
}

\begin{abstract}
In the diverse research on Multi Commercial Complexes, rather than a technical and statistical approach, it is now time to focus on the quality of urban sustainability based on the daily experience of urban residents. Therefore, this research proposes a mechanism for making a sophisticated adjustment to the "Ground", defined as the empty space of a designated site under the existing urban conditions, towards planning the sustainability of a Multi-Commercial Complex. For the first step, the elements of urban sustainability were extracted from the Figure-Ground Theory and the urban theory of Aldo Rossi and Kevin Lynch, respectively. The relationship between the methodology, which deals with the concept of "Ground" and its sustainable urban status, is analyzed using five selected multi-commercial complex cases. We derived the characteristics of "Ground" represented in each case, including "Responding", "Contextual", "Historical", "Co-existing", and "Hybrid" sustainability. In each case, the "Ground" was treated as a crucial common issue. In this paper, we suggest that preferential consideration and sensitive design of the "Ground" are crucial for maintaining urban sustainability in the planning of Multi Commercial Complexes. This paper can thus contribute to the body of research on urban sustainability along with existing technical studies.
\end{abstract}

Keywords: Multi Commercial Complexes; urban sustainability; features of the "Ground"; contextual inference; Figure-Ground theory; passive circulation; amenity; mobility; flexibility

\section{Introduction}

As a type of composite development, Multi Commercial Complexes have been strongly influenced by the type and direction of urban development. In contemporary society, Multi Commercial Complexes not only provide functional accommodation, but also have economic, social, and cultural influences on urban sustainability [1]. We therefore need to pay more attention to how Multi Commercial Complexes establish relationships with urban environments as a way of stimulating sustainable urban daily life. The Multi Commercial Complex is a representative form of multi-purpose development in contemporary society, which combines commercial facilities and one or more primary function uses, and is developed to bring synergetic effects by combining the appropriate functions. Recently, the role of these facilities as spaces of cultural consumption and their economic effects has been focused on, and these facilities are being actively developed as part of a vitalization strategy for contemporary cities.

As the supply and demand of Multi Commercial Complexes is increasing, multifaceted research is in progress, and technical approaches [2] in particular have been increasing. Technical studies are studies based on more statistical and quantitative information such as analyzing the air quality within a shopping mall, using the methodologies that deal with the ventilation system, and a technical index. 
Accordingly, the objective of this research is to analyze the quality of urban sustainability [3] from a more intuitive, imaginative perspective, while considering that the day-to-day practical experience of urban residents ensures the quality of this urban sustainability. This perspective takes into account the causal relationships of how users receive information from their surroundings and how they interpret and perceive them.

To meet this objective, this research analyzes relevant cases by combining Aldo Rossi's theory, Kevin Lynch's Image of the City theory and the Figure-Ground theory [4]. As a result, this will show that the sustainability of the Multi Commercial Complex relies on the surrounding urban context and on the sensitive tuning of the Ground.

This study selected Multi Commercial Complexes with historical, regional, and cultural backgrounds [5] that had been built during a time of increased urban development around 2000, when composite development was actively being performed [6]. The complexes have also exerted influences on the surrounding environments since their development.

Five cases were selected that demonstrate environmental sustainability, and were assessed as places that have a socially positive influence on the contemporary city. Further, these cases are effectively culturally performed by the citizens from the perspectives of the "Ground".

In this study, we derived that the major factor that makes urban sustainability possible is [7] the "Ground" [8], which is defined as the open spaces of a designated site. In the designated site, if an empty space is simply a space devoid of anything, an open space is one that has the potential for engaging in new activities; because the site is empty, one may see images of other cities through the empty space, and experience a greater variety of activities from these images. If an empty space is defined using a physical standard, an open space is a concept emerging from a utilization-based perspective [9]. Therefore, we analyzed the process and the accompanying detailed positive effects of sustainability in planning a Multi Commercial Complex with a focus on the methodology that deals with the "Ground" (Figure 1).

\section{Theoretical Study}

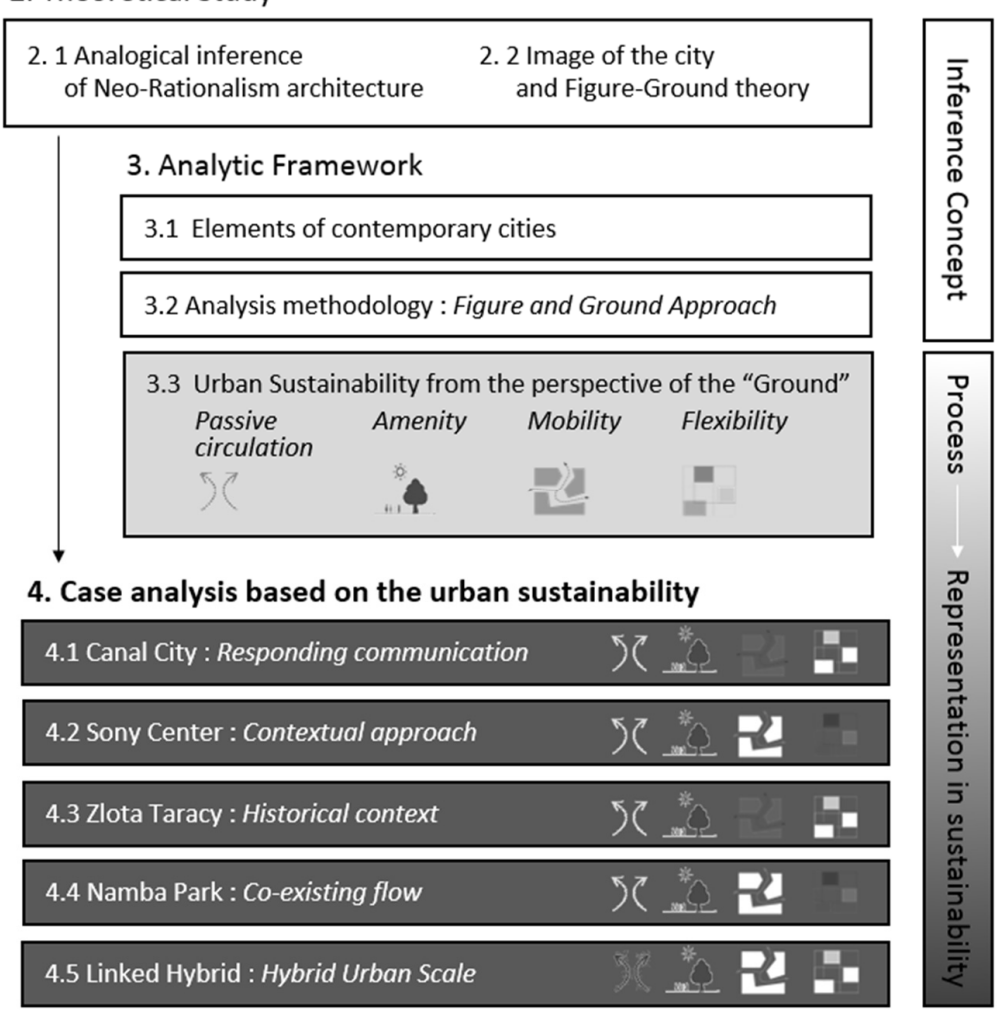

Figure 1. Logical connections between chapters. 
Data on examples of Multi Commercial Complexes were collected and an on-site survey was conducted for some of these examples. The contributions made by the complexes to the image of the urban context, the behaviors of their users, and their relationships with the urban contexts were also examined. Based on these data, analysis was carried out on the conditions before and after development, the methods used to connect urban elements, the motifs used, and the design process of architectural complexes. Finally, through this study, the methods and reasons for developing new urban spaces can be illustrated and focus will be placed on the public socio-cultural role [10] of empty spaces and places for the quality of sustainability in the urban context [11].

\section{Theoretical Study}

The present study takes into consideration valid historical-theoretical theories based on urban contexts in order to propose a contemporary interpretation of urban contexts. A popular topic today is the rehabilitation of urban public spaces in contemporary cities [12]; but not only has the concept of public space existed since the birth of cities, it is also regarded as important and evolving, depending on the nature of the urban development. Accordingly, in the present study, more attention needs to be paid to the relationships between architecture and the urban context in terms of public space on the basis of urban theories [13].

\subsection{Analogical Inference of Neo-Rationalism Architecture}

Having emerged in Italy in the 1930s, the style of neo-rationalism architecture was based on functional clarity and economic utility; it focused on the importance of history and space for contemporary architects who sought new styles of architecture. Aldo Rossi, an architect of neo-rationalism in Italy, understood the relationships between city and architecture in two respects. First, he viewed a city as a very large organism, as a composite architecture that has grown over time. Second, he saw a city as a building structure specialized by an urban form and an architecture composing an urban form. Using these terms, a city can be summarized according to a typological architecture, in which a type of architecture is understood by its urban form. Rob Krier and Leon Krier approached the concept of type in terms of urban form. They systematically analyzed the types and transformations of urban spaces comprising squares and streets [14].

Neo-rationalism's acceptance of the urban context is expressed in its urban characteristics, and linguistic methods are used as the basis of supplementary relationships between the city and architecture. The typological approach to urban architecture, as seen in neo-rationalism, is a significant method used to assist the recovery of urban identity.

\subsection{Image of the City and Figure-Ground Theory}

The aim of the Figure-Ground theory [15] is to analyze cities using urban images and assumes that an urban image consists of order, verticality, rhythm, and movement [16]. These elements enable a space to achieve a balance between symmetry and asymmetry. As a basic element, order is found in the arrangement, collection, and layout of urban buildings, streets, and square elements. This sense of order created by the built environment helps us to feel comfortable while walking through streets in Europe. A building exists not just for its own sake, but also as a type of "Figure" to support the "Ground" (in reference to Rossi's theory), the latter of which is an empty space or place according to the Figure-Ground theory. Therefore, the building's meaning and experience depend on the entire urban context, and becomes important in the image of the urban form. Therefore, the "Ground", which is the outside area of a building, also possibly communicates with the building users. Such interaction occurs anywhere in spaces where citizens live.

Hence, the "Grounding" technique how to design empty spaces in the designated site, is as significant as any other type of "figuring", and is used as a design strategy. Besides, the principle of "inference", which applies to the urban image, is today also reproduced in combination with physical, synesthetic, and behavioral aspects as well as visual aspects, regardless of the era. The above theories will be applied to the work in the following sections [17]. 


\section{Analytical Framework}

In the birth and the development of cities, squares and markets were urban spaces that played important public roles. However, Multi Commercial Complexes and surrounding spaces play similar roles in the contemporary era. This is because they have become spaces representing the life and culture of citizens rather than merely places for buying and selling goods. As consumption activities strengthen the social roles of commercial spaces, the public functions of these spaces need to be taken into consideration. This is why contemporary commercial spaces are changing into multi-commercial spaces with public functions, although they are not public spaces in the traditional sense. Considering this viewpoint, Multi Commercial Complexes are representative facilities that intentionally perform public functions [18]. For this reason, Multi Commercial Complexes are becoming increasingly more intentional as part of the planning of sustainable urban projects and are closely related to urban issues [19].

\subsection{Elements of Contemporary Cities}

Urban elements have been defined in diverse ways in a range of urban theories. Kevin Lynch, Aldo Rossi, Oswald Matias Ungers, Rob \& Leon Krier, and Pepper variously classified the city into districts, passages, boundaries, nodes, and landmarks, with the basic elements including residential sectors, urban landscape, block structure, square (plaza) and street, texture, quality, and context. In post-modern urban theories, the city was divided into tangible (physical, direct, and visual) and intangible (indirect, cultural, and social) factors. In this way, the components of a city varied according to the viewpoints of the various ages [20].

The present study will define urban elements on the basis of the urban contextual elements presented by post-modern theories that refer to public aspects. In the relationships between architecture and the city, the elements are roughly classified into physical, cognitive, and socio-behavioral factors.

First, the physical factors are the visual and tangible elements that consist of natural features, such as water and mountains, and artificial features such as buildings and built form. Natural elements are subdivided into topography, climate conditions, landscape, natural color tones etc.; artificial elements are subdivided into construction materials, scale, form and contour, height, window/door arrangement/size, front side, color, neighboring buildings, etc.

Second, the cognitive elements correspond to the historical or transcendental urban memories or images that suggest cultural or social contents. They include historical authenticity, symbolism, place, the spirit of the times, tradition, openness, etc.

Third, socio-behavioral elements are based on the rules, value system or institution of the urban environment. They comprise public space, proximity, social space, regional character, function/use, legal conditions, institution, economic feasibility, etc.

Various urban elements are applied in Multi Commercial Complexes on the basis of the above-mentioned elements. First, the natural elements are the neighboring landscape, natural features, land, climate conditions, etc.; second, cognitive elements include place, symbolism, historicity, etc.; third, the socio-behavioral elements include public space, accessibility, openness, etc. These factors are applied in various ways in a city. The analysis in the following section will show the intentions of these factors and how they have been materialized [21].

\subsection{Analysis Methodology: Figure-Ground Approach}

In terms of the urban context, Multi Commercial Complexes are analyzed using two processes [22]: the design priority as a background prior to the construction of building structures and the secondary process that occurs after the construction. The above-mentioned urban theories [23] are considered to be significant interpretations that focus on the fact that Multi Commercial Complexes influence their neighboring contexts after the construction of the building [24]. In summary, primary and secondary processes are performed by the interpretation and realization of urban elements and the formation of new urban images, respectively [25]. 
Firstly, the interpretation of urban elements refers to the background in which multi facilities are planned. In urban terms, the development motives that include contextual inferring considerations are very important in that they are the driving forces for architecture, and have decisive influences on the planning and the design strategy. At this stage, urban elements are directly applied or analytically presented to address problems and critical conditions. Based on these circumstances, a process of inference is carried out in various forms. Multi-functional facilities are represented through urban history, image, and nature because they are formed from their relationships with a city.

Secondly, the urban elements are embodied through the process of specific and practical planning to express urban elements with building structures. In this process, the construction process is carried out by applying the Figure-Ground theory in which urban space is interpreted based on the relationships between "filled areas" (buildings) and "empty areas" (squares and roads). The Figure refers to the architectural (or positive) form on a site and the Ground refers to an empty area along with architectural spaces such as paths or open spaces [26]. Next, a study is carried out of the way in which the planned examples create a new urban image in the city. In this regard, urban cross-sections were investigated to examine the relationships between the city and architecture. A suggestion was then extracted from the analysis of the relationships between city and architecture. Because Multi Commercial Complexes constantly interact with the existing urban context (line of movement, method of entry, intersection of gazes, and the relationship with the surrounding environment), studying the cross-section of the architecture in contact with the city and buildings is essential.

\subsection{Urban Sustainability from the Perspective of the "Ground"}

From the perspective of the "Ground" [27], we define the way in which to represent urban sustainability as passive circulation in the environmental issue, amenity from the contemporary surroundings, mobility (Figure 2) in approaching accessibility and flexibility in functional and cognitive extensibility [28]. Urban sustainability, from the perspective of the urban context in the contemporary city, implies a propensity for continuance that may be realized by various spaces, people, activities, and images. Since the citizens' perceived image of the city and their expectations of its circumstances are more important in contemporary cities than the pre-existing image of the city, efforts to extend the sustainability of the city are very meaningful. Such sustainability is created by the citizens, as they understand it. Normally, urban users' cultural performances in the Ground tend to be derived from the natural and social relationships.

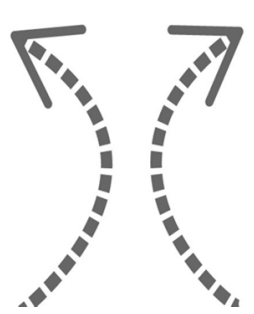

(a)

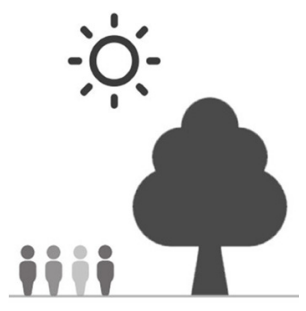

(b)

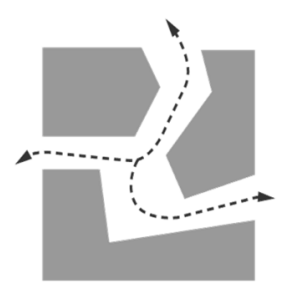

(c)

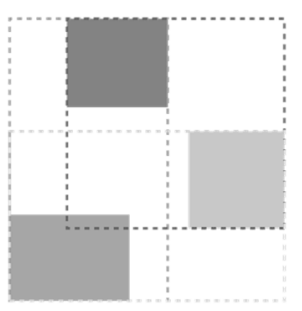

(d)

Figure 2. Representations of urban sustainability. (a) Passive circulation (b) Amenity (c) Mobility (d) Flexibility.

\subsubsection{Passive Circulation}

Passive circulation refers to the sustainable architectural requirements in the environmental sense [1]. The most important planning requirement for sustainable building is to plan for natural circulation and self-sustainable measures for temperature control of the internal environment without resorting to any mechanical devices. Above all, this will be emptying the building complexes for the ventilation and circulation, which is one of critical functions of the "Ground". 


\subsubsection{Amenity}

From an urban perspective, the "Ground" area, which is the space that is open for the urban residents or the users in a Multi Commercial Complex, can play the role of the image of a sustainable city that urban residents can enjoy and form new memories, serving as an amenity area [29] that enables breaks, meetings, memories, events, etc., among commercial areas [30].

\subsubsection{Mobility}

Mobility [29] is a concept that includes accessibility, and if accessibility focuses more on the ease of access of the inner portion of the facility from outside, mobility becomes a circulation-based concept that includes aspects such as entering into the facility from outside, reaching outside from within the facility, and the free flow of movements within the facility [31]. Mobility can be divided into mobility from the outside, which creates natural access to the building from the city, and internal mobility that facilitates horizontal or vertical transportation within the facility. The former especially relates to the city's context. The way in which outdoor space, the "Ground" can be manipulated around the building is an important planning factor that determines whether or not the relationship between the building and its surroundings is sustainable.

\subsubsection{Flexibility}

"Ground" creates diverse and flexible situations. Depending on the type of surrounding and grouped features of the building, the ground can provide both a semi-external and a semi-internal sense of space. Depending on the acceptance of situational programs, the open space can be changed to become a stage or a service space for extended use of commercial facilities or temporary events. This will become an important planning requirement of sustainable complex facilities as the most effective space planning principle among future complex facility uses.

\section{Case Analysis Based on the Urban Sustainability}

From the perspective of urban sustainability, selected cases were analyzed by contextual inference and design process in the view of the Figure and Ground. (Table 1).

\subsection{Canal City (Fukuoka, Japan, 1996)}

\subsubsection{Contextual Inference and Figure-Ground Design Process}

Canal City (Figure 3) was designed to offer a dramatic place where the architectural building itself actually forms a city. A canal was constructed in a parallel direction with the flow of the river, to encourage people entering from the road to move with the direction of the canal.

The goal of Canal City was to incorporate the feature of the river, a major natural element in the urban context, with the architecture [32]. In terms of the Figure-Ground, the "Ground" was considered in the form of a canal, and the Figure as the architectural building was then designed along with the canal. Namely, the design process involved first forming the "Ground" and then forming the "Figure". This process was innovative as it represents the reverse order of the typical way in which architecture is designed.

While squares were traditionally formed in front of building structures as the vacant spaces remaining after the building has been erected, here the empty space is the canal, namely the "Ground". The "Figure", comprising the building structures, was formed in the remaining area. The three-dimensional Figure technique was applied so that the empty areas could be open towards the city, with streets and external corridors opening into the building structure. 
Table 1. Contextual inference and design process in the view of the Figure and Ground in each case.

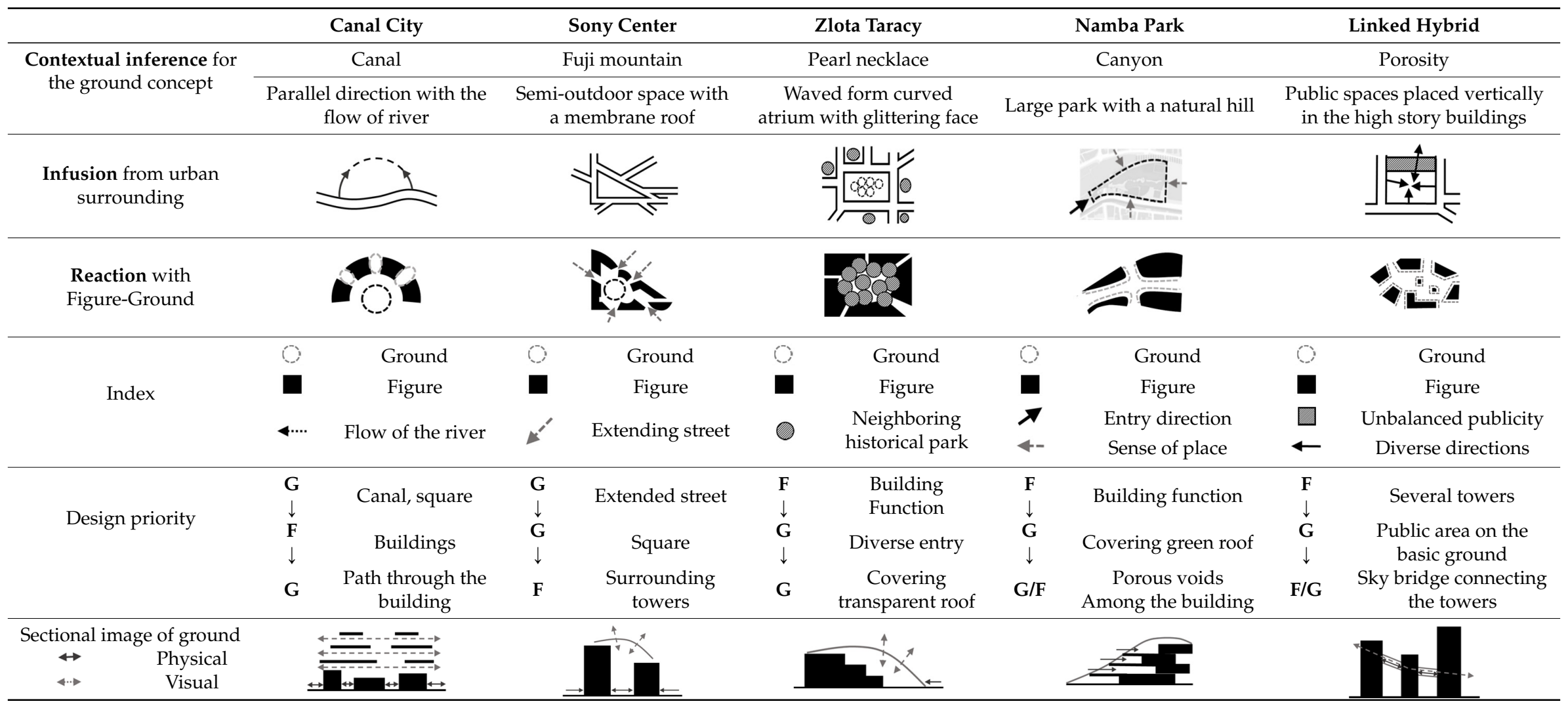




\subsubsection{Urban Sustainability: Responding Communication}

In terms of passive circulation in the Canal City building, air was naturally circulated through the externalized corridor across the building, which is the Inner "Ground", and was designed to be a self-sustainable environment with a water space, which is the Outer "Ground", as the waterway.

In terms of the amenity at Canal City, the architectural environment, which combines these two Grounds, acts as the space where urban residents can come together and take a break while experiencing nature. With the synesthetic effects of light, sound, and water, the passages in each floor were transformed into guest seating areas on a waterside stage, creating a new urban image in which the people almost become street performers.

The canal as the "Ground" acts as an environmental element enabling citizens to move to destinations through water routes and gather together in a square.

From the view of flexibility, Canal City, which extends the role of the "Ground", not only serves as a commercial space for commercial enterprise, but also an architecture with flexible functions and that can coexist with urban residents, enabling people to enjoy sustainable and diverse experiences, depending on the situation.

Each floor functions as one of the open images toward the city shown in the cross-section by encircling each function with a corridor, a public space. The external curved corridors on each floor interconnect along curved surfaces towards the upper and lower parts, creating interesting shadows from the dynamic space and light.

However, in one aspect, the externalized common spaces such as the corridors easily showed signs of deterioration because of direct exposure to the external environment. Because the spaces could not benefit from the heating and cooling infrastructure in the summer and winter seasons, people stopped using the spaces.

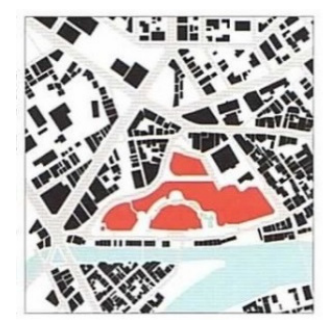

(a)

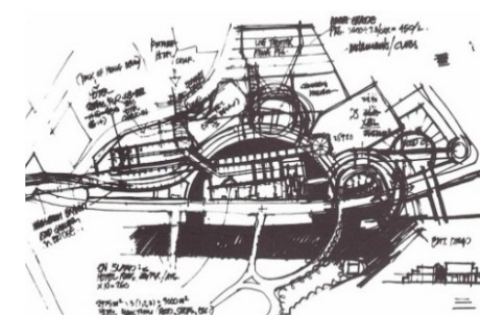

(b)

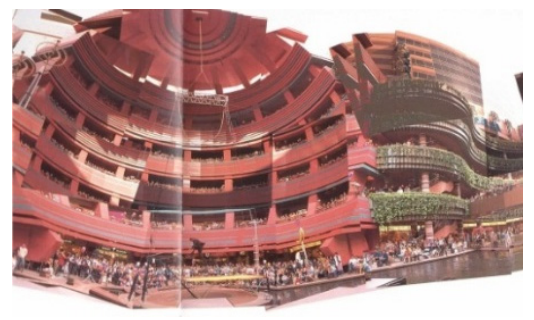

(c)

Figure 3. Canal City in the urban contextual inference and the Figure-Ground process [32].

(a) Figure-Ground image; (b) Site plan; (c) Perspective image.

\subsection{Sony Center (Berlin, Germany, 2000)}

\subsubsection{Contextual Inference and Figure-Ground Design Process}

The Sony Center (Figure 4) is important in urban and historical terms. In Europe, the Potsdam Square, which has become a center with a great deal of traffic since the 1920s, has attracted much attention due to its symbolism and potential as a hub of financial activities. The square was interpreted as a site of historical restoration and a meeting place for Berlin citizens through its historicity and meaning of place [33]. To represent the historical expression of the site, in the Sony Center, the representation of the urban space on a small size was realized by extending streets from the city. The original is too vague. In terms of Figure-Ground, the "Ground" elements were formed by extending the streets. A large forum of a stadium shape, namely the "Ground", became the area where the streets met. The "Figure" was then formed by arranging seven buildings around the square. Public facilities, such as commercial and cultural buildings, were arranged only around the forum and more private buildings were arranged on rear layers separating the public areas from the private areas, similar to that in practical urban organizations. 


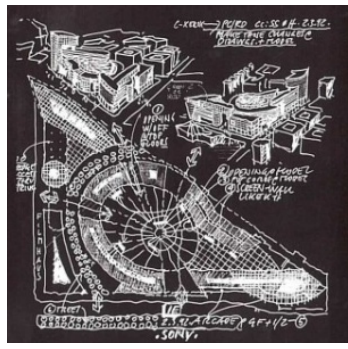

(a)

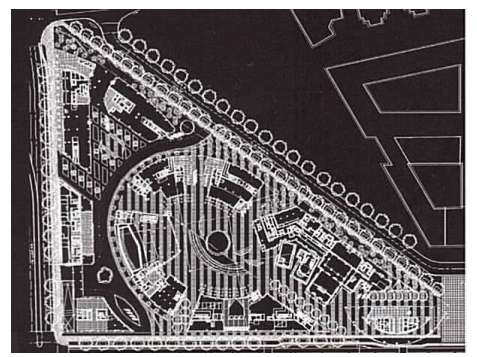

(b)

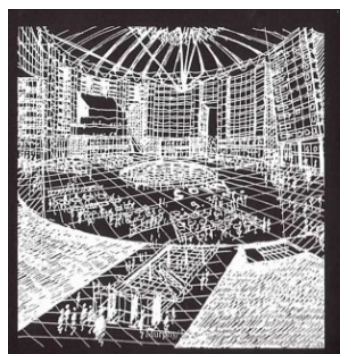

(c)

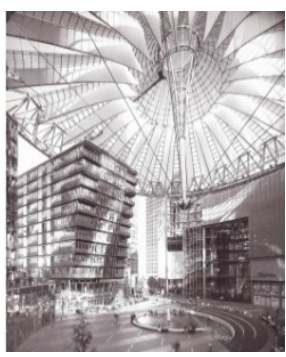

(d)

Figure 4. Sony Center in the urban contextual inference and the Figure-Ground process [33]. (a) Figure-Ground image; (b) Site plan; (c) Perspective image; (d) Interior image.

\subsubsection{Urban Sustainability: Contextual Approach}

The design enabled pleasant indirect sunlight to enter the building from the roof of the membrane structure, which is the public Ground. The plaza, which is the basic "Ground", formed by horizontal lines that extended from the surrounding context and formed on a node, achieves a pleasant environment where there is air circulation. This has meaning as a place of amenity where urban residents can relax and enjoy meeting each other.

From the perspective of amenity, the square inside the group of buildings played the role of creating a new urban image by acting as a meeting plaza. Citizens experience the reduced urban façade along with the plaza where they can feel the space as a semi outdoor space with a roof membrane structure. This acts as an amenity, enabling citizens to enjoy rest and meeting others.

The surrounding streets, straddled by paths that extend from the basic grounds formed on the ground floor, maximize the accessibility, allowing people who approach the building to move about in the pleasant semi-external plaza.

From the view of flexibility, the "Ground", which is the extended and open streets of cities that have historical significance, is not only used as a path making physical connections, but also as a path of flexibility by serving as a window from which to look out at the visually open city.

Seen from the city, the building structures are associated with neighboring contexts and have identical facades in each node. At each entrance located in each node, the width, height, and design of the voids are connected with neighboring buildings, allowing the new architecture to maintain the historical context. This makes the perception of path flexible. Further, the frame of view towards the city is flexible, as it is adjusted according to the historical context of each path.

In comparison to the natural expansion of the street structure, the membrane roof that was modeled after the image of Mount Fuji has been critiqued. The roof's design is thought to be quite removed from the urban context and historic meaning, while imparting an alienating impression in forming the image of the city.

\subsection{Zlota Taracy (Warsaw, Poland, 2007)}

\subsubsection{Contextual Inference and Figure-Ground Design Process}

The Zlota Taracy (Figure 5) was developed to create space that could give urban vitality to an area in which the functions were lost after the long-term devastation of the Second World War. A metaphorical interpretation was given to natural elements to realize urban components as lively images. The goal of Zlota Taracy was to build a transparent "creature" that glittered like a pearl. Therefore, neighboring historical parks that had been protected from the war were interpreted as valuable "pearls"; the name Zlota Taracy, i.e., "pearl necklace" is derived from this concept. The glittering curved face of a pearl is represented by the wave-form curved atrium roof, which houses lively indoor/outdoor scenes [32]. 


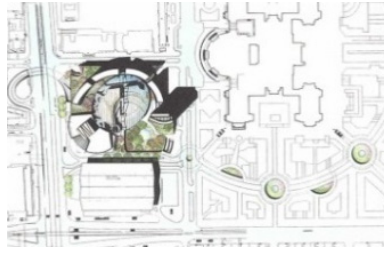

(a)

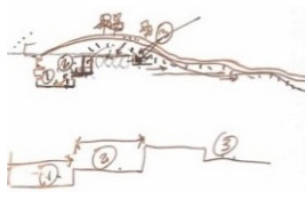

(b)

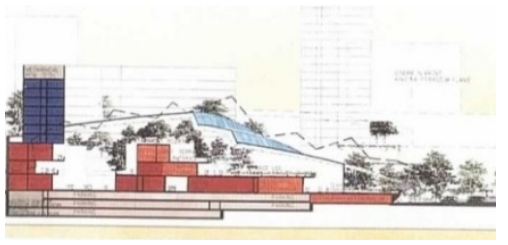

(c)

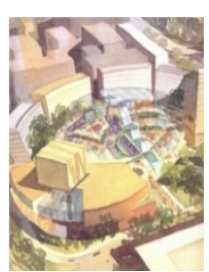

(d)

Figure 5. Zlota Taracy in the urban contextual inference and the Figure-Ground process [32]. (a) Figure-Ground image; (b) Sectional diagram; (c) Section; (d) Perspective image.

In terms of Figure-Ground, the Figuring technique was applied in an unprecedented way, as it allowed visual communication through the half transparent glittering skin. People on each level of the building can feel the semi-indoor space with the atrium curved from the roof to the ground, making a three-dimensional "Ground" façade.

\subsubsection{Urban Sustainability: Historical Context}

In terms of passive circulation, the wave ceiling type atrium space, which is the "Ground", created an environment where the lighting effect was maximized by the light reflected in different directions, even though the atrium space is outdoors.

From the perspective of amenity, a wave-form atrium was set up by applying the shape of a pearl necklace to the internal architecture. A large wave-form ceiling covering a central square has a roof that is undifferentiated from the wall surfaces, forming a new urban image by realizing an open form that can communicate with the neighboring context.

In the view of mobility, large internal spaces allow entry from each direction to make it easier to enter from the surrounding streets not only for visual accessibility of Zlota Taracy but also physical accessibility. Through the open atrium, we can easily read the movement of people inside the building.

From the view of flexibility, the "Ground" area, which is completely open to the commercial facilities on each floor, can be utilized flexibly because each facility can be expanded as needed.

The building that is closed off visually in entirety by the atrium brings to mind memories and images of the city, while also resulting in weakening accessibility and the flow of movement in part in reality.

\subsection{Namba Park (Fukuoka Japan, 2007)}

\subsubsection{Contextual Inference and Figure-Ground Design Process}

Namba Park (Figure 6) was designed to revitalize various urban functions, while maintaining the public nature of a regionally important place in Namba, Osaka, where a baseball park was relocated to another site. The goal was to suggest a building structure as a park by interpreting the sense of place as a memory of the former baseball park site and the practical necessity of a park. This made it possible to provide a natural environment to a high-density urban area [32].

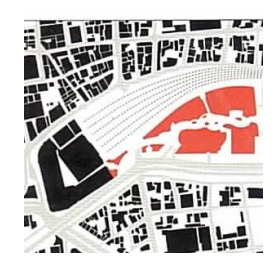

(a)

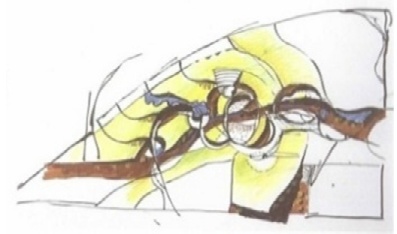

(b)

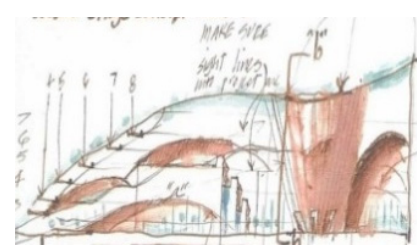

(c)

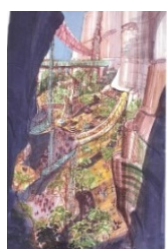

(d)

Figure 6. Namba Park in the urban contextual inference and the Figure-Ground process [32]. (a) Figure-Ground image; (b) Site plan; (c) Sectional diagram; (d) Perspective image. 
In terms of Figure-Ground, a dynamic horizontal space was formed by the empty space, "Ground" in the form of a park, along the entry direction. The commercial spaces accumulated on the hill side act as the "Figure". This creates a large park with a natural hill form.

\subsubsection{Urban Sustainability: Co-Existing Flow}

The "Ground" in Namba Park is the roof of the commercial area, which is open like a park. As it is connected to the ground level, the roof not only prevents the heat island effect, but is also a passive circulation space that has excellent heat insulation property.

In Namba Park, the formal characteristics of a canyon were used as a direct design element by introducing the theme of the canyon, which is not a traditional element in the urban context, but represents a large natural form. Therefore, this creates a fresh urban image, which plays a significant role in realizing the sustainable amenity of the city.

In terms of mobility, the structure was made accessible from the ground through the roof acting as a park. The building structure is open on various levels, and is connected to the space of each floor via a garden of a natural hill shape. The total commercial zone, symbolizing the canyon, was flexible for extending existing spaces or adding new functions by creating the "Ground" through the buildings.

Covering the entire building with afforested gardens resulted in more weight than what was required, causing a structural burden and generating the need for additional facilitative systems such as precipitation management. It was impossible to avoid the critical situations caused by anthropogenic elements of nature.

\subsection{Linked Hybrid (Beijing, China, 2009)}

\subsubsection{Contextual Inference and Figure-Ground Design Process}

The Linked Hybrid (Figure 7) project was carried out as part of an urban revitalization project coupled with the redevelopment of a paper-mill site built according to the industrialization policy of Beijing, China. In understanding the urban components, Steven Holl began with the critical interpretation of public areas in this region. He pointed out the considerable gap between the city and its citizens with the increasing emergence of vertical towers and the unbalanced layout of public areas. He focused on the fact that high-rises exist not as a singular massive figure, but as small blocks. He focused on the possibility that public spaces could be placed vertically in high-rise buildings by connecting the buildings to each other [34].

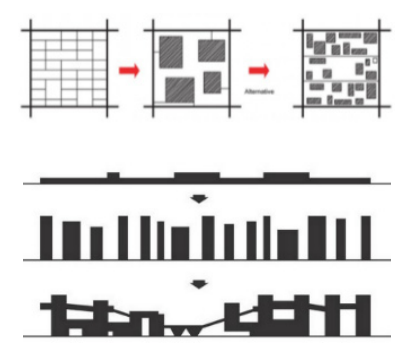

(a)

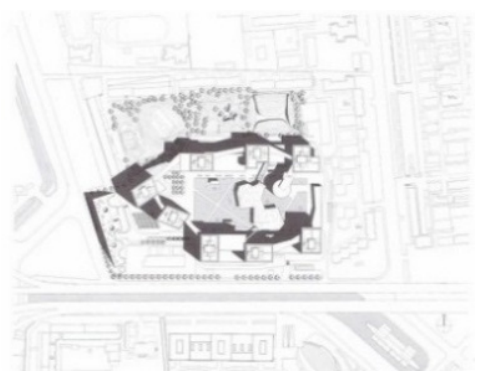

(b)

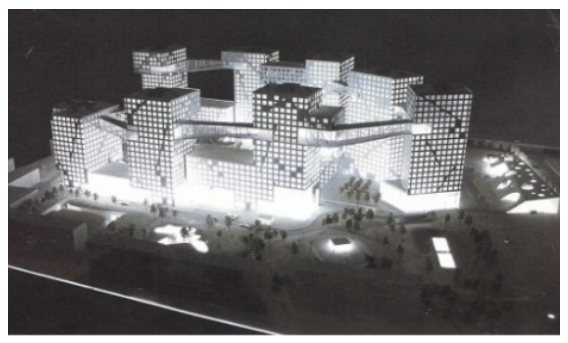

(c)

Figure 7. Linked Hybrid in urban contextual inference and Figure-Ground process [34]. (a) Figure-Ground process; (b) Site plan (c) Perspective image.

In terms of the Figure-Ground, in the Linked Hybrid project, public areas were arranged by creating the "Ground" space through streets to enable pedestrians to move in diverse directions at the entry ground level. A public space on the 18th floor connects the towers in the air. Thus, the "Ground", comprising common services with transparent glass enveloping empty space, hangs vertically within the "Figure", whereby several towers consist of building structures. 


\subsubsection{Urban Sustainability: Hybrid Urban Scape}

The city of the Linked Hybrid project is surrounded by compact buildings, whereby the circulation of air and open views are possible through the open first floor area, which is an exterior space surrounding a pond with natural vegetation and five hills, which is a self-sustainable area that became the sustainable environment.

This gives a new unprecedented direction to the design of high-density urban multi-use building structures. Several groups of tower-form structures are connected to each other via bridges, forming spaces in the air.

Thus, the "Ground", which realized the new concept of vertical horizontality in public space, provides more availability of amenities and greater comfort for the residents.

In Linked Hybrid, an idea was borrowed from urban development to form a new urban image. Porosity [35] organizations were designed in the building structure to vitalize the closed public spaces and arrange them freely even though they were generated within massive complexes that emerged from past urban organizations.

Likewise, the open ground area of the first floor serves as a space open to the public, so the accessibility and usability have been maximized. By including many spaces (that is, the "Ground" in each floor), the possibility of being redirected to a different area or adding new functions in the future has been increased. This demonstrates that it is possible to plan for flexible space in a dense city.

On the first ground level, open spaces and an open flow of movements were possible, but because of the differences in the standard of living from that of surrounding regions, the alienating effect from its neighbors was heightened. This also played a role in inducing a gated community.

\section{Conclusions}

The methodology used to manipulate the "Ground" (Table 2) in contemporary Multi-Commercial Complexes directly relates to the quality of urban sustainability. That is, the urban spaces and buildings in the city have longevity if open spaces of Multi Commercial Complexes are made sustainable. After interpreting the urban context and "Ground", a full-scale design should proceed based on the interpretation.

In terms of urban sustainability, the present study analyzed urban spatial organizations in terms of the contextual perspective by examining how Multi-Commercial Complexes can manipulate the Ground, and how they can renew the existing urban components, based on the Figure-Ground theory. The following is a summary of the findings of this work. Canal City created a new sense of place as a cognitive element having synesthetic qualities combined with the natural river element by utilizing the concept of Inner Ground and Outer Ground within the site. The Sony Center created Extended Ground by expanding the existing streets into building structures, providing an open public area, and thus adding new socio-behavioral elements to the city. Zlota Taracy, in which the Ground is within the atrium, comprised a visual park to connect the past with the present by creating a space where memorable images and openness are emphasized by the architectural reinterpretation of historical parks. Namba Park is a hill type park using public space and symbolism to provide public places, enhancing the socio-behfavioral aspects, in a city lacking in public places, and the roof was used as an urban park. The Linked Hybrid project infused new vitality into an urban facades by addressing the absence of public areas in a high-rise context by creating a Hanging Ground within the vertical voids, making the building porous and thus enhancing proximity between people through the Basic Ground. 
Table 2. Cross interpretation from the perspective of urban sustainability according to the "Ground" concept.

\begin{tabular}{|c|c|c|c|c|c|}
\hline & Canal City & Sony Center & Zlota Taracy & Namba Park & Linked Hybrid \\
\hline \multicolumn{6}{|l|}{ Ground concept } \\
\hline & $\begin{array}{l}\text { Inner } \\
\text { Ground }\end{array}$ & $\begin{array}{l}\text { Extended } \\
\text { Ground }\end{array}$ & \multirow[t]{2}{*}{ d } & \multirow[t]{2}{*}{$\begin{array}{l}\text { Ground } \\
\text { through the }\end{array}$} & $\begin{array}{l}\text { Basic } \\
\text { Ground }\end{array}$ \\
\hline & $\begin{array}{l}\text { Outer } \\
\text { Ground }\end{array}$ & Open ground & & & $\begin{array}{l}\text { Hanging } \\
\text { Ground }\end{array}$ \\
\hline \multirow{2}{*}{ A. Passive circulation } & Externalized corridor & Theroof of a membrane & Waved atrium & Natural formed roof & Emptied 1st floor \\
\hline & Outdoor environment & Pleasant indirect lighting from & Natural ventilation & Commercial area as a park & Natural environment \\
\hline \multirow{2}{*}{ B. Amenity } & $\begin{array}{l}\text { Guest seating area in } \\
\text { a waterside }\end{array}$ & Semi outdoor square & $\begin{array}{l}\text { Communication with } \\
\text { neighboring contexts }\end{array}$ & Park with natural form & $\begin{array}{l}\text { Towers connected via } \\
\text { bridges }\end{array}$ \\
\hline & Cooperative stage & Historical memory & A new urban image & Resting or gathering & Hybrid urbanscape \\
\hline \multirow{2}{*}{$\begin{array}{c}\text { C. Mobility } \\
\text { 니 }\end{array}$} & Water routes & Active movement & Emptied atrium & $\begin{array}{l}\text { Open structures with } \\
\text { various levels }\end{array}$ & $\begin{array}{l}\text { Hanging ground on the } \\
\text { 20th floor }\end{array}$ \\
\hline & Easy access from the city & Square open to the city & $\begin{array}{l}\text { Leading the active } \\
\text { movement }\end{array}$ & Access from each levels & $\begin{array}{c}\text { Convenient common } \\
\text { services }\end{array}$ \\
\hline \multirow{2}{*}{ D. Flexibility } & $\begin{array}{l}\text { Diverse experiences } \\
\text { upon the situations }\end{array}$ & $\begin{array}{l}\text { Extended streets }+ \text { paths }+ \\
\text { framing void }\end{array}$ & $\begin{array}{l}\text { Expanded facility } \\
\text { toward the atrium }\end{array}$ & Outdoor roof as a park & $\begin{array}{l}\text { Sky bridge and } \\
\text { Emptied 1st floor }\end{array}$ \\
\hline & Cognitive & Physical/Visual & Functional & Physical & Cognitive/Physical \\
\hline
\end{tabular}


Analyzing each example from the perspective of urban sustainability revealed them to be unique ways according to the interactive relationship between natural and cultural performances [36]. In Canal City, the water space extended from the canal, a natural element, and the verdant areas were arranged abundantly along the first floor and the externalized corridor across the building, thereby creating a sense of flexible harmony for each circumstance among the natural, architectural, and cultural performances that appear in the space. Through the externalized corridor, air was naturally circulated, allowing for both flexibility and passive circulation. In Sony Center, the semi-outdoor space with a membrane roof in an enjoyable natural environment enables people, society, and cultural performances to enter through the extended street and harmonize together. This illustrates the highlighting of the elements of passive circulation and mobility. Zlota Taracy attempted to maximize natural environment in the indoor space as well through the atrium. Although it does not feel like nature itself, one may say that the space became more pleasant, and natural and cultural performances were held from the perspective of imbuing the city with a new image and vitality. The characteristics of passive circulation and amenity are manifested here. Namba Park materialized nature directly in the form of a park, thereby creating a verdant space for rest and leisure activities in the middle of a dense city center surrounded by buildings; this park provides mobility in an accessible manner with possibilities of improving amenities to expand the cultural activities of citizens. Linked Hybrid placed the community program, which used to occupy the first floor, into a vertically hung arrangement emptying the first floor area and making the passive circulation of air possible. By organically arranging the natural elements, the verdant and water spaces, the surrounding cultural flow can naturally be extended; therefore, the passive circulation and mobility perspectives are emphasized.

In conclusion, this study discussed the various methods to interpret and materialize urban elements in terms of urban sustainability and the ensuing potential for new urban images. This research, along with recent advanced technical studied, has facilitated a more essential interest in Ground that is directly connected to the richness of urban life. This has considerable significance in that it seeks a balance in academic research through focusing more on the social and essential issues with advances in technology and statistical approaches.

Acknowledgments: This work was supported by 2016 Hongik University Research Fund.

Author Contributions: All of the authors contributed equally to this work. All authors have read and approved the final manuscript.

Conflicts of Interest: The authors declare no conflict of interest.

\section{References}

1. Domique, G.M. Sustainable Architecture and Urbanism; Springer Berlin Heidelberg: Berlin, Germany; Heidelberg, Germany, 2002; pp. 34-35, 92-121.

2. Netzband, M.; Stefanov, W.L.; Redman, C. Applied Remote Sensing for Urban Planning, Governance and Sustainability; Springer Berlin Heidelberg: Berlin, Germany; Heidelberg, Germany, 2007; pp. 1-19.

3. Beniamino, M.; Giuseppe, B.; Alessandra, L. Geocomputation, Sustainability and Environmental Planning; Springer-Verlag: Heidelberg, Germany; Berlin, Germany, 2011; pp. 1-16.

4. Wortham-Galvin, B.D. The Woof and the Warp of Architecture: The Figure-Ground in Urban Design. Delft Archit. Theory J. 2010, 7, 69-73.

5. Vojnovic, I. Urban Sustainability: A Global Perspective; Michigan State University Press: East Lansing, MI, USA, 2012; pp. 1-34.

6. Van Der Heijden, J. Governance for Urban Sustainability and Resilience: Responding to Climate Change and the Relevance of the Built Environment; Edward Elgar Publishing: Cheltenham, UK, 2015; pp. 124-152.

7. James, P. Urban Sustainability in Theory and Practice: Circles of Sustainability; Taylor and Francis: Abingdon, UK, 2014; pp. 22-24.

8. Thwaites, K. Urban Sustainability through Environmental Design: Approaches to Time, People, and Place Responsive Urban Spaces; Routledge: Abingdon, UK, 2007; pp. 27-52.

9. Baofu, P. The Future of Post-Human Urban Planning: A Preface to a New Theory of Density, Void, and Sustainability; Cambridge Scholars Publishing: England, UK, 2009; pp. 169-223. 
10. Manzi, T.; Lucas, K.; Jones, T.L. Social Sustainability in Urban Areas: Communities, Connectivity and the Urban Fabric; Taylor and Francis: Oxfordshire, UK, 2010; pp. 105-159.

11. Bovill, C. Sustainability in Architecture and Urban Design; Routledge Tayer \& Francis group: Abingdon, UK, 2015; pp. 199-216.

12. Colantonio, A.; Dixon, T. Urban Regeneration and Social Sustainability: Best Practice from European Cities; John Wiley \& Sons: New York, NY, USA, 2010; pp. 54-80.

13. Nadarajah, M.; Yamamoto, A. Urban Crisis: Culture and the Sustainability of Cities; Wiley-Blacjwell: Hoboken, NL, USA, 2006; pp. 1-79.

14. Aldo, R. L'architettura Della Citta; The Institute for Architecture and Urban Studies and The Massachusetts Institute of Technology: Cambridge, MA, USA, 1982; pp. 9-13.

15. Roelfsema, P.; Lamme, V.; Spekreijse, H.; Bosch, H. Figure-Ground Segregation in a Recurrent Network Architecture. J. Cogn. Neurosci. 2002, 14, 525-537. [CrossRef] [PubMed]

16. Linch, K. The Image of the City; The MIT Press: Cambridge, MA, USA, 1960.

17. Lee, S.H.; Song, D.H. A study and the urban characteristics in Architecture of Neo-Rationalism. Proc. Archit. Inst. Korea 2012, 8, 301-304.

18. Vanderhoeven, F.; Rosemann, H.J. Urban Transformations and Sustainability; IOS Press: Amsterdam, The Netherland, 2006; pp. 57-66.

19. Dixon, T.; Eames, M.; Hunt, M.; Lannon, S. Urban Retrofitting for Sustainability: Mapping the Transition to 2050; Taylor and Francis: Abingdon, UK, 2014; pp. 333-374.

20. Kim, E. Urban design and notional changes in the concept of publicness over time. J. Digit. Design. 2008, 1, 478-486.

21. Woo, J.H.; Kim, U. A Study on the public space planning based on figure \& ground theory in urban image. Proc. Archit. Inst. Korea 2008, 52, 237-240.

22. Matthew, I.S. Sustainability in America's Cities; Island Press: Washington, DC, USA, 2011; pp. 1-20.

23. Metzger, J.; Rader Olsson, A. Sustainable Stockholm: Exploring Urban Sustainability in Europe's Greenest City; Taylor and Francis: Abingdon, UK, 2013; pp. 71-101.

24. Pavel, M.P. Breakthrough Communities: Sustainability and Justice in the Next American Metropolis; The MIT Press: Cambridge, MA, USA, 2009; pp. 1-106.

25. Boone, C.; Fragkias, M. Urbanization and Sustainability; Springer Netherlands: Dordrecht, The Netherlands, 2012; pp. 18-20.

26. Sanders, J.C. Seattle and the Roots of Urban Sustainability: Inventing Ecotopia; Pittsburgh History of the Urban Environment; University of Pittsburgh Press: Pittsburgh, PA, USA, 2010; pp. 99-130.

27. Birch, E.L.; Wachter, S.M. City in the Twenty-First Century: Growing Greener Cities: Urban Sustainability in the Twenty-first Century; University of Pennsylvania Press: Pennsylvania, PA, USA, 2008; pp. 1-10.

28. Vollmer, D. Pathways to Urban Sustainability: Lessons from the Atlanta Metropolitan Region; National Academies Press: Washington, DC, USA, 2011; pp. 24-26.

29. Williams, D.E. Sustainable Design: Ecology, Architecture, and Planning; John Wiley \& Sons, Inc.: Hoboken, NJ, USA, 2007; pp. 18-19, 69-79.

30. Henn, R.L.; Hoffman, A.J.; Biggart, N.W. Urban and Industrial Environments: Constructing Green: The Social Structures of Sustainability; The MIT Press: Cambridge, MA, USA, 2013; pp. 197-217.

31. Schröpfer, T. Ecological Urban Architecture: Qualitative Approaches to Sustainability; Birkhauser-Publisher for Architecture: Berlin, Germany, 2012; pp. 80-119.

32. Bradbury, R. You Are Here: The Jerde Partnership International; Phaidon Press Limited: London, UK, 1999.

33. Werner, B. Helmut Jahn Architecture Engineering; Birkhauser-Publisher for Architecture: Berlin, Germany, 2002; pp. 40-59, 40-42.

34. Cecilia, F.M.; Levene, R. Steven Holl Architects_Selected Works 2003/2008; El Croquis Editorial: Madrid, Spain, 2008; pp. 226-247, 478-486.

35. Kim, S. Steven Holl's Approaches and Planning Characteristics Based on Urban Porosity in the Multi Complexes. J. Archit. Inst. Korea 2014, 319, 478-486. [CrossRef]

36. Weinstein, M.P.; Turner, R.E. Sustainability Science: The Emerging Paradigm and the Urban Environment; Springer: New York, NY, USA, 2012; pp. 64-65.

(c) 2016 by the authors; licensee MDPI, Basel, Switzerland. This article is an open access article distributed under the terms and conditions of the Creative Commons Attribution (CC-BY) license (http://creativecommons.org/licenses/by/4.0/). 